Section Editors

David C. Spencer, MD

Steven Karceski, MD

Jake L. Kaufman, BA

Steven Karceski, MD

\title{
Risk factors and prevention of lacunar infarcts in 60- to 64-year-olds
}

WHAT DID THE AUTHORS STUDY? In their study "Prevalence, incidence, and risk factors of lacunar infarcts in a community sample" (Neurology ${ }^{\circledR}$ 2009;73:266-272), Chen et al. studied the frequency of certain kinds of stroke, called lacunar stroke (also called infarction). Using MRI scans of the brain, they found out how common lacunar infarctions were in a sample of healthy people living in Australia. In addition, the authors looked at how often new strokes occurred, and they studied whether the old strokes changed over time. Finally, they tried to see if there were any risk factors that lead to this kind of stroke. By figuring out how and why lacunes form, doctors can better understand how to look for them and how to prevent them from happening.

The people in the study were 60 to 64 years old. They were recruited from the PATH Through Life study, a large, ongoing study that is following the health of people recruited at random from the Australian cities of Canberra and Queanbeyan. To find people for the study, Chen et al. sent letters to 4,832 individuals within the age range. About 2,500 people agreed to help with the study, and from this group, 1 in 5 was selected at random to participate. A total of 478 individuals (252 men and 226 women) took part in the study. Each person had an MRI scan and clinical examination when the study began ("wave 1"). Four years later, they had a second scan and were examined again ("wave 2"). By performing the same tests 4 years apart, the investigators could learn the changes that occurred over time.

In both waves, the clinical examination included measuring blood pressure, taking blood samples, and collecting cells from the inside of the mouth to analyze DNA. Subjects were divided into 3 categories according to blood pressure: definite hypertension (too high), borderline hypertension, and normotensive (normal blood pressure). Diabetes, smoking, and alcohol histories were noted, and blood glucose was measured to screen for undiagnosed diabetes. In both waves, MRI scans were performed to look for the specific kind of lacunar strokes in each person's brain.

When looking for lacunes in MRI scans, the authors had to define the qualities of a lacunar infarct very precisely. In this way, Chen and his colleagues had better agreement among researchers about what was and what was not a "lacune." They defined a lacune as a small area of empty space in the brain measuring between 0.5 and 2 centimeters. All proposed lacunes were doublechecked by a neuroradiologist (a doctor who specializes in examining MRIs of the nervous system). This radiologist was not informed about the history or clinical findings of the patients, so his decision about the strokes was without this potential bias. To prove that their method of detecting lacunes was consistent and valid, the researchers looked at how often different investigators agreed about what was a lacune and what was not. They found that their method for defining lacunes produced $89 \%$ agreement among the researchers. This suggests that the definition used for a lacunar infarct was precise and consistently applied to the data, lending strength to the study's conclusions.

Once lacunes were identified, their size was measured. White matter hyperintensities (WMHs), which are bright spots on the MRI found in the parts of the brain containing nerve fibers, were noted and measured. In addition, the size of the brain ventricles-the large chambers of CSF within the brainand the size of the whole brain were measured. Finally, the hippocampus and amygdala-brain structures that tend to be abnormal in patients with memory and thinking problems - were measured.

The study found that $7.8 \%$ of study participants had at least one lacunar infarct in their wave $1 \mathrm{MRI}$ and $0.6 \%$ had more than one. In the group of people who reported that they had had a stroke in the past, $20 \%$ had lacunes on their MRI. An association was detected between having a lacune and having high blood pressure, though there was no similar relation between blood pressure and lacune size. The ratio of ventricle size to total brain size (the ventricle-brain ratio, VBR) in the front of the brain was higher in patients with lacunar infarcts. Similarly, the presence of lacunes was associated with a larger amount of WMHs. In wave 2, 8.8\% of people were found to have lacunes. Six subjects (1.6\%) had new lacunes not detected in wave 1, and 3 of those 6 had not had any lacunes at all in wave 1 . Unfortunately, because so few new lacunes developed, no statistically significant conclusions could be drawn about the risk factors associated with developing new lacunes.

WHY ARE THE FINDINGS IMPORTANT? The findings in this study confirm other theories and may help guide 
public health projects aimed at stroke prevention. Lacunes are known to become more common as people get older, so in a large group of people, most of the lacunes will be in the older individuals. The study's finding of silent lacunar infarcts in $7.8 \%$ of 60 - to 64 year-olds, and the detection of new lacunes in $1.6 \%$, is very similar to what other studies have found. Chen and coauthors demonstrated a strong association between high blood pressure and the risk of lacunar infarction, as have past studies (with some slight differences). No association was found with diabetes, smoking, alcohol, weight, cholesterol, or gender.

WMHs may result from problems with small blood vessels in the brain causing oxygen starva- tion for brain cells. This mechanism of disease is similar to that of lacunes, but it is unclear whether WMHs and lacunes are caused by the same vessel problems or share the same risk factors. This study confirmed the general relationship between WMHs and lacunes, but found them to have different risk factors. This study confirms the importance of controlling blood pressure in preventing vessel disease in the brain. The precise causes of lacunar infarction are still unknown, but studies like this can help doctors better understand how and why these diseases develop, which is important to improving treatment, diagnosis, and prevention guidelines. 
Section Editors

David C. Spencer, MD

Steven Karceski, MD

\section{About lacunar infarcts}

WHAT IS A LACUNAR INFARCTION? Lacunes are small areas inside the brain where poor blood flow has starved a group of cells of oxygen. Lack of oxygen causes the cells to die. When this happens, it is called a stroke or an infarction. A lacunar infarct is a tiny stroke that often causes no neurologic symptoms (these are also referred to as "silent" strokes). While many healthy people have silent lacunes, some association has been shown between having lacunes and having mild problems with thinking. When a person has a lot of lacunes, or when they occur in certain key parts of the brain, dementia may develop. When the dementia is due to many small strokes, it is called vascular dementia ("vascular" means "related to blood vessels," and blockage of the blood vessel causes strokes).

WHAT CAUSES LACUNAR INFARCTIONS AND WHAT ARE THE SYMPTOMS? In general, infarctions occur when not enough blood or oxygen is getting to parts of the brain. This can be caused by a clot, by bleeding, by blood or nutritional disease, or by diseases that cause vessels to close or narrow. One of the major causes of vessel disease in the brain is hypertension (high blood pressure), which is established as a risk factor for all strokes, including lacunar infarcts. Although doctors do not know the precise cause of lacunar infarctions, they are still thought to be due to disease of the blood vessels. Unlike strokes, lacunar infarctions are often not noticed by patients, though subtle symptoms sometimes can be present (trouble with memory or thinking).

WHO HAS LACUNAR INFARCTIONS AND HOW DO YOU TREAT THEM? Except with vascular dementia, lacunes are not usually symptomatic and represent a marker of blood vessel disease in the brain. The study of lacunes is not targeted toward treatment, but rather toward understanding why they form. With that understanding, doctors hope to understand strokes in general. Studies like this one have confirmed that hypertension is associated with vessel disease in the brain. Also, stroke prevention programs should include blood pressure reduction among their goals.

\section{HOW COMMON ARE STROKES AND HOW ARE} THEY TREATED? Approximately 600,000 Americans have a new stroke every year. Strokes can cause a wide variety of symptoms, from mild and temporary problems, to physical and mental disability, to death. Stroke prevention is like heart attack prevention. Patients should care for their cardiovascular health through weight control, blood pressure control, control of diabetes, and living in a healthy way. Hypertension is the single most significant risk factor, but heart disease, smoking, diabetes, high cholesterol, and other causes of vessel disease have been shown to contribute to stroke risk.

When stroke symptoms begin, it is very important to go to a hospital quickly. Medicine can be given and actions can be taken right away to save infarcted areas of the brain from dying permanently. If begun as quickly as possible after symptoms of a stroke begin, these treatments can reduce long-term symptoms and even save patients' lives. Symptoms such as sudden numbness or weakness of half of the face or body, sudden loss of consciousness, confusion, or difficulty talking can be seen as signs of a possible stroke. People having these symptoms should go to an emergency room as quickly as possible.

\section{FOR MORE INFORMATION}

American Stroke Association

www.strokeassociation.org

National Institute of Neurological Disorders and Stroke

http://www.ninds.nih.gov/disorders/stroke/stroke.htm

National Stroke Association

http://www.stroke.org/site/PageNavigator/HOME

Centers for Disease Control and Prevention

http://www.cdc.gov/strokel

Internet Stroke Center

http://www.strokecenter.org/patients/index.html 


\section{Neurology}

\section{Risk factors and prevention of lacunar infarcts in 60- to 64-year-olds \\ Jake L. Kaufman and Steven Karceski \\ Neurology 2009;73;e17-e19 \\ DOI 10.1212/WNL.0b013e3181b3ac61}

This information is current as of July 27, 2009

\section{Updated Information \&}

Services

Permissions \& Licensing

Reprints including high resolution figures, can be found at:

http://n.neurology.org/content/73/4/e17.full

Information about reproducing this article in parts (figures,tables) or in its entirety can be found online at:

http://www.neurology.org/about/about_the_journal\#permissions

Information about ordering reprints can be found online:

http://n.neurology.org/subscribers/advertise

Neurology ${ }^{\circledR}$ is the official journal of the American Academy of Neurology. Published continuously since 1951, it is now a weekly with 48 issues per year. Copyright. All rights reserved. Print ISSN: 0028-3878. Online ISSN: 1526-632X.

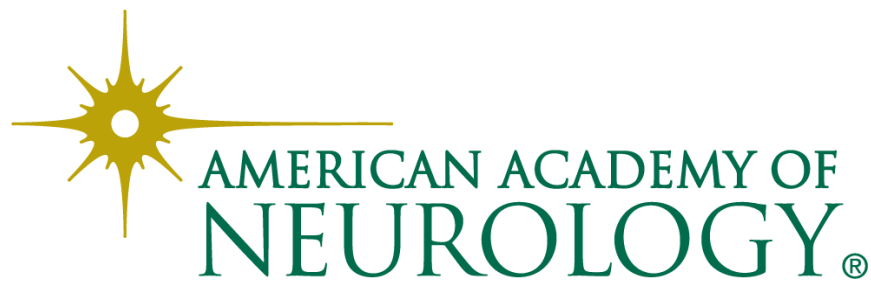

